\title{
TECHNIKA „GŁOŚNEGO MYŚLENIA” W TŁUMACZENIU NA JĘZYK OJCZYSTY NA POZIOMIE ZAAWANSOWANYM
}

DOI: http://dx.doi.org/10.12775/RP.2015.015

\begin{abstract}
Zarys treści: Artykuł porusza problem przekładu jako środka dydaktycznego w procesie uczenia się i nauczania języka obcego. Na podstawie protokołów głośnego myślenia dokonano analizy tłumaczeń studentów neofilologii w celu określenia rodzaju i częstotliwości użycia strategii uczenia się podczas tłumaczenia z języka niemieckiego na język polski. Dla potrzeb opisu strategii uczenia się w tłumaczeniu przedstawiono także wybrane przykłady trudności, jakie badani mieli w trakcie przekładu na język ojczysty.
\end{abstract}

Słowa kluczowe: protokoły głośnego myślenia, proces uczenia się i nauczania języka obcego, strategie uczenia się, język ojczysty

\section{Wstęp}

\uzaą popularnością wśród studentów kierunków filologicznych cieszy się zawód tłumacza. Z moich rozmów ze studentami wynika, że większość z nich chciałaby po studiach zostać tłumaczami przysięgłymi. Niestety ich wyobrażenia o pracy tłumacza i samym procesie tłumaczenia są bardzo często mylne. Tak zresztą zwykle bywa u adeptów różnych profesji, nie tylko w przypadku zawodu tłumacza. Studenci uważają na przykład, że tłumaczenie na język ojczysty jest łatwiejsze od tłumaczenia na język obcy. Dlatego z perspektywy dydaktyki przekładu wydało mi się ciekawe zbadanie przebiegu procesu tłumaczenia jak i rezultatów tego procesu, tj. tłumaczeń na język polski, tu niemieckiego tekstu zawierającego wybrane przykłady nomenklatury z zakre- 
su nauk ścisłych, dokonanych przez studentów III roku Lingwistyki Stosowanej Uniwersytetu Kazimierza Wielkiego w Bydgoszczy w ramach przedmiotu Praktyczna Nauka Języka Niemieckiego - pisanie z ortografią.

Niniejszy artykuł składa się zatem z dwóch zasadniczych części. W pierwszej przedstawię przebieg procesu tłumaczenia, opierając się na technice głośnego myślenia i zapisywania przez studentów wszelkich komentarzy, jakie im się nasunęły w trakcie przekładu. Dzięki temu mogłam określić rodzaj i częstotliwość użycia przez nich strategii uczenia się w tłumaczeniu tekstu. W czasie tej analizy moją uwagę zwróciły liczne wątpliwości, jakie mieli studenci, tłumacząc tekst na język ojczysty. Dlatego w drugiej części niniejszych rozważań omówię wybrane przykłady trudności językowych, jakie towarzyszyły studentom podczas tłumaczenia z języka niemieckiego na język polski.

Tłumaczenie zarówno z języka ojczystego na język obcy, jak i z języka obcego na język ojczysty ma funkcję kształcącą i powinno być integralną częścią procesu nauki języka każdego studenta neofilologii. Ćwiczenia tłumaczeniowe integrują różne sprawności i umiejętności językowe, udoskonalają kompetencje językowe obydwu języków, rozwijają kompetencję interkulturową, pozwalają świadomie przyswajać sobie język, uczą właściwego korzystania ze słowników jedno- i dwujęzycznych, uwrażliwiają na różnice strukturalne, leksykalne oraz kulturowe pomiędzy językami, rozwijają kreatywność studentów, kształtują precyzję w wyrażaniu myśli, a także poszerzają ich wiedzę ogólną (Grucza 1981: 33; Jäger 1981: 66; Königs 2000: 9-10; Płusa 2007: 12).

\section{Pojęcie strategii uczenia się i ich klasyfikacja}

Wszyscy używamy strategii zarówno w życiu codziennym, aby coś zapamiętać (np. numery PIN, NIP, PESEL), jak i podczas nauki języków obcych (np. gdy uczymy się słownictwa, gramatyki czy tłumaczymy teksty).

W procesie nauki języka obcego strategie są specyficznymi elementami zachowania się uczących, potrzebnymi do nauczenia się języka oraz do regulowania procesu uczenia się. Strategie są nastawione na rozwiązywanie określonych problemów podczas przyswajania, gromadzenia oraz stosowania nabytych informacji językowych np. w trakcie przekładu z jednego języka na drugi (Michońska-Stadnik 1996: 30-31; por. także Szarska-Wieruszewska 2004: 68; Strasser 2008: 46).

Jest wiele klasyfikacji strategii uczenia się języka. Dla potrzeb niniejszego artykułu przyjęłam podział Rebeki Oxford (1990) (Michońska-Stadnik 1996: 38-40; Szarska-Wieruszewska 2004: 87-92) na: 


\section{A. Strategie bezpośrednie:}

1) strategie pamięciowe, np. tworzenie skojarzeń myślowych (umiejscawianie słów w kontekście), używanie słów kluczy, wykorzystywanie podobieństwa graficznego;

2) strategie kognitywne, np. powtarzanie, kombinowanie struktur, używanie różnych technik ułatwiających rozumienie tekstów pisanych lub słuchanych, używanie dodatkowych źródeł dla usprawnienia biernej i czynnej znajomości języka, np. słowników i leksykonów, analizowanie danych językowych (dedukowanie, porównywanie z językiem ojczystym lub innym językiem obcym, tłumaczenie); wyciąganie wniosków, użycie wyobraźni;

3) strategie kompensacyjne, np. zgadywanie przy użyciu wskazówek lingwistycznych, szukanie pomocy, unikanie rozmowy, opuszczanie słów czy zwrotów podczas tłumaczenia, dostosowanie tekstu do swoich potrzeb, tworzenie nowych słów, użycie synonimu lub omówienia.

\section{B. Strategie pośrednie:}

1) strategie metakognitywne, np. wiązanie nowych informacji ze znanym materiałem, koncentrowanie się na wybranym zagadnieniu czy aspekcie języka, planowanie, tj. organizowanie wypowiedzi, monitorowanie, czyli skupianie uwagi na określonym zadaniu czy określonej informacji, ocenianie własnej produkcji językowej;

2) strategie emocjonalne, np. słuchanie muzyki, stosowanie metod relaksacyjnych, śmiech, pozytywne uwagi na temat swoich postępów, pochwała, rozmowa $\mathrm{z}$ innymi o swoich uczuciach czy osiągnięciach;

3) strategie społeczne, np. zadawanie pytań, prośba o wyjaśnienie, współpraca $z$ innymi uczącymi się, porównywanie notatek, wspólne rozwiązywanie problemów językowych, „mówienie do siebie” (przekonywanie i upewnianie samego siebie, np. że dane zadanie jest prawidłowo wykonane).

\section{Metodologiczne podstawy badań}

W programie kształcenia studentów lingwistyki na UKW nie ma przedmiotu Języki specjalistyczne, którego celem byłyby m.in. językowa analiza tekstów fachowych oraz poznawanie i utrwalanie nowego słownictwa specjalistycz- 
nego. Ponieważ kształcenie studentów na studiach neofilologicznych nie może być ograniczane wyłącznie do nauczania języka obcego ogólnego, pracuję ze studentami na zajęciach z Praktycznej Nauki Języka Niemieckiego pisanie $\mathrm{z}$ ortografią także $\mathrm{z}$ tekstem specjalistycznym. W ramach praktycznej nauki języka studenci tłumaczą krótkie teksty fachowe o niewysokim stopniu trudności, ponieważ nie mają dostatecznych kompetencji tłumaczeniowych i nie znają jeszcze podstawowych strategii translatorskich. Ale dzięki takim ćwiczeniom poznają nowe słownictwo z określonej dyscypliny, utrwalają dotychczasową wiedzę językową w zakresie obydwu języków oraz poszerzają swoją wiedzę ogólną zdobytą w toku zajęć akademickich.

Przedmiotowe badanie przeprowadziłam w ramach zajęć Praktyczna Nauka Języka Niemieckiego - pisanie z ortografią, w maju 2013 r. wśród studentów III roku Lingwistyki Stosowanej kombinacji język angielski z językiem niemieckim oraz język niemiecki z językiem rosyjskim studiów pierwszego stopnia Uniwersytetu Kazimierza Wielkiego w Bydgoszczy (30 osób). Studenci zostali dokładnie poinformowani o celu i zasadach badania. W czasie zajęć tłumaczyli krótki tekst (zob. rys. 1) o Carlu Friedrichu Gaußie (1777-1855), niemieckim matematyku, fizyku, astronomie i geodecie, twórcy geometrii nieeuklidesowej, uważanym za jednego z trzech, obok Archimedesa i Newtona, największych matematyków świata, nazywanym „księciem matematyków" (Encyklopedia szkolna. Matematyka 1990: 68)

Wszyscy studenci otrzymali egzemplarz przywołanego tu tekstu na wcześniejszych zajęciach, aby w ramach pracy domowej mogli zapoznać się $\mathrm{z}$ jego treścią.

Poprosiłam studentów, żeby zapisywali cały proces swojego tłumaczenia, tj. wszystkie swoje wątpliwości, towarzyszące myśli, nasuwające się uwagi i pomysły, co w literaturze przedmiotu nazywa się techniką „głośnego myślenia" (za: Michońska-Stadnik 1996: 116-126). Teksty studentów, czyli tłumaczenia wraz z komentarzami, zebrałam i poddałam analizie. W ten sposób ich prace stały się moim materiałem źródłowym i równocześnie narzędziem badawczym, które pozwoliło mi obserwować zachowania językowe uczących się w trakcie przekładu. Dostarczyło mi to odpowiedzi na pytanie, jakich strategii uczenia się podczas tłumaczenia tekstu zawierającego fachowe słownictwo $\mathrm{z}$ języka obcego na język ojczysty, tu z języka niemieckiego na język polski, i jak często używają osoby na poziomie zaawansowanym. Dzięki temu mogłam nie tylko poznać strategie, które pojawiają się w interjęzyku badanych podczas tłumaczenia, lecz także zrozumieć działania najczęściej podejmowane przez studentów, potrzebne im do regulowania procesów uczenia się języka, tu ułatwiające im zrozumienie tekstu w języku wyjściowym. Dla 


\section{* Carl Friedrich Gauß}

C. Fr. Gauß wurde am 30.4. im Jahre 1777 in Braunschweig geboren. In jenem Augenblick konnte niemand ahnen, daß er später einmal in der ganzen Welt „Princeps mathematicorum" genannt werden würde und daß er auch auf den Gebieten der Astronomie, der Physik und der Chemie Großes erreichen sollte.

Als Sohn eines Saisonarbeiters wuchs Gauß in ärmlichen Verhältnissen auf. Der Fürst von Brauns shweig erkannte frühzeitig sein Genie und bildete ihn aus. Seine Meisterschaft in der Mathematik bewies er schon als 9-jähriger Knabe in der Schule in Braunschweig. Während einer Schulstunde fand er bei der Addition der Zahlen von 1-100 die Summenformel der arithmetischen Reihe. Mit 15 Jahren hatte er die wichtigsten mathematischen Werke durchgearbeitet und machte mit 17,18 und 19 Jahren wichtige mathematische Entdeckungen. Mit 20 Jahren erhielt er den Doktortitel an der Universität in Helmstedt. Bis zu seinem Tode im Jahre 1855, also fast 50 Jahre, arbeitete er als Direktor der Sternwarte und Professor der Astronomie an der Universität in Göttingen. Er wandte sich der Astronomie $\mathrm{zu}$, und auch hier gelang ihm eine berühmte Entdeckung. Der

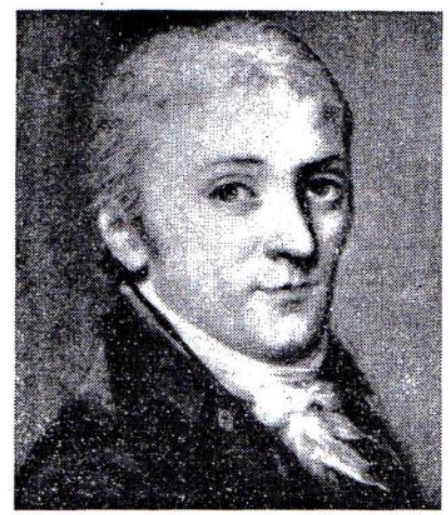

Carl Friedrich Gauß (1777-1855) Standort des Planeten Ceres, der nur einmal gesehen worden war, wurde von Gauß berechnet, und der Planet wurde genau an der berechneten Stelle gefunden. Berühmt wurden außerdem seine Erdvermessungen und die Miterfindung des elektromagnetischen Telegraphen. Gauß war aber vor allem einer der größten Mathematiker aller Zeiten, der auf vielen Gebieten dieser Wissenschaft bahnbrechend wirkte und Weltruhm genoß.

Unabhängig von Euler entdeckte er den Beweis des Reziprozitätsgesetzes der quadratischen Reste. In seinen ersten Dissertationen erbrachte er den Beweis für den Fundamentalsatz der Algebra, wonach jede algebraische Gleichung (reelle oder komplexe) Lösung hat. Hier zeigte er seine Meisterschaft beim Gebrauch der komplexen Zahlen. Die Geometrie hat Gauß bereichert durch den Lehrsatz, daß die Seiten eines regulären Siebzehnecks nur mit Hilfe des Zirkels und Lineals gebaut werden können. Über die Verdienste des graßen Mathematikers wäre noch viel zu sagen. Er war genial. Aber nicht nur seine Fähigkeiten waren Hauptmotor seines wissenschaftlichen Wirkens: Hauptmator war seine große Liebe zur Mathematik.

Rys. 1.

Źródło: Lelewicz, Linkiewicz 1967. 
potrzeb opisu specyfiki strategii uczenia się w tłumaczeniu na język ojczysty wyniki badań uzupełniłam wybranymi przykładami trudności językowych, jakie towarzyszyły badanym $\mathrm{w}$ trakcie przekładu. Podczas analizy prac studentów zauważyłam, że badani nie potraktowali tego ćwiczenia jako nudne czy niepotrzebne. Niektórzy bardzo się zaangażowali, co widać było po stronie technicznej ich tekstów, np. aby wyróżnić swoje myśli, zaznaczali je gwiazdkami, podkreślali na kolorowo, robili odnośniki, tłumaczyli na marginesie to, co chcieli dokładnie wyrazić. Studenci podeszli poważnie do zadania. Tylko trzy osoby oddały kartki z wykonanym tłumaczeniem, które nie zawierało żadnych uwag. Studenci mogli podczas pracy korzystać ze słowników, o przyniesienie których poprosiłam ich na wcześniejszych zajęciach; były to słowniki jedno- i dwujęzyczne ogólne oraz specjalistyczne. Dodam, że ćwiczenie nie było oceniane.

Z uwagi na ograniczone ramy niniejszego artykułu chciałabym krótko przypomnieć, że metoda głośnego myślenia została zapoczątkowana w psychologii pod koniec XIX wieku, gdy próbowano odkryć tajemnice ludzkiej świadomości. W latach 80 . XX wieku zaczęto ją stosować w badaniach nad tłumaczeniem, aby zrozumieć, co się dzieje w umyśle tłumacza. Analizę protokołów głośnego myślenia w translatoryce opracował Paul Kussmaul (1995), dla którego celem badań z zastosowaniem techniki głośnego myślenia była m.in. obserwacja tłumaczenia kreatywnego. Pozwoliło to uświadomić sobie mechanizmy psychologiczne i językowe towarzyszące tłumaczeniu, poznać strategie stosowane przez tłumaczących i zastosować je później w dydaktyce przekładu (Witkowska 2010: 148, 151).

\section{Przykłady strategii stosowanych podczas tłumaczenia tekstu z języka obcego na język ojczysty}

\section{Strategie pamięciowe}

1. Skojarzenia, np. „Entdeckungen kojarzą mi się z odkryciami w fizyce i chemii, a czy można coś odkryć w dziedzinie matematyki?”, „Fundamentalsatz kojarzy mi się z fundamentalnym zdaniem, ale czy może być fundamentalne zdanie?”, „Die Summenformel der arithmetischen Reihe kojarzy mi się ze zwrotem formuła sumujaca arytmetycznego rzędu, tylko czy jest coś takiego?”, „Komplexe Zahlen kojarzą mi się z kompleksowymi liczbami, ale nie pamiętam z lekcji, czy były takie liczby". 
2. Wykorzystanie kontekstu podczas rozumienia tekstu, np. „Werke znam tłumaczenie: dzieła, a czy tu będzie to w tym kontekście?”, „Der Fürst von Braunschweig erkannte sein Genie - rozpoznał jego geniusz, a może w tym kontekście będzie to talent?”, „Wachsen to rosnać, ale nie można rosnąć w rodzinie, chyba napiszę dorastał lub wychowywał się".

\section{Strategie kognitywne}

1. Dedukowanie, np. „Nie wiem, jak przetłumaczyć Summenformel, muszę to rozbić na Summe i Formel, czyli sumę i wzór - wzór sumy", „Bahnbrechend - Bahn to kolej, a brechen to łamać, to może chodzi o łamanie drogi pod tory, czyli dać jakąś podwalinę”, „Verhältnisse to stosunki, ale tu chyba chodzi o warunki w rodzinie, a nie stosunki”.

2. Dosłowne tłumaczenie wybranych słów czy struktur na język ojczysty, np. „Mit 17, 18 und 19 Jahren przetłumaczę słowo w słowo jako mając 17, 18 i 19 lat", „Die arithmetische Reihe - napiszę dosłownie rząd arytmetyczny, bo Reihe to rzad”, „Während einer Schulstunde - czy napisać podczas lekcji? Lepiej napiszę podczas jednej godziny lekcyjnej”, „Summenformel - napiszę formuła sumy, tak wynika z tłumaczenia wyrazów”, „[...] und der Planet wurde genau an der berechneten Stelle gefunden - i ta planeta została dokładnie na obliczonym miejscu znaleziona - przetłumaczyłam dokładnie, ale Ania ma inaczej”.

3. Kombinowanie struktur w dwóch językach, np. Der Fürst Brunszwiku, Księstwo Braunschweig, Książę Braunschweig, Książę von Braunschweig, Księstwo von Braunschweig, na uniwerytecie w Göttingen.

4. Analizowanie międzyjęzykowe, $\mathrm{np}$. „Na uniwersytecie w Helmstedt czy można przetłumaczyć nazwę miasta na polski?”, „Princeps mathematicorum przetłumaczyć jako książe matematyki, książę nauk matematycznych a może zostawić Princeps mathematicorum?”, „Princeps mathematicorum - tłumaczyć czy nie?”.

5. Analizowanie danych językowych pod względem stylistycznym, np. „Dokonać ważnych przełomowych odkryć - czy przełomowy w odniesieniu do ważny w tym kontekście nie jest nadużyciem?”, „[...], dass er später - że on podać imię i nazwisko w nawiasie (C.F. Gauß)?", "Auf vielen Gebieten - w wielu dziedzinach czy na wielu płaszczyznach, co tu wyrazić?”, „bahnbrechend to będzie przełomowy czy pionierski, co brzmi tu lepiej?”, „der... wirkte - wplywat czy miat wielki wplyw?”, „in ärmlichen Verhältnissen - w skromnych warunkach - skromnych czy biednych? biedne warunki? - chyba nie”, "Jego geniusz rozpoznat 
książę Brunszwigu - nie jestem pewna, czy można rozpoznać geniusz, lepiej chyba jego talent został odkryty przez księcia Brunszwigu”, „Majac dwadzieścia lat uzyskat - uzyskat czy otrzymał tytuł doktora?”, „An der Universität in Helmstedt - czy uniwersytet w Helmstedt jest nazwą własną i tworzy całość?”, „Als Sohn eines Saisonarbeiters jako syn pracownika sezonowego czy sezonowego pracownika?”, „als 9-jähriger Knabe - chłopiec czy chłopak?”, „Während einer Schulstunde fand er bei der Addition der Zahlen von 1-100 - podczas godziny lekcyjnej czy zajęć lekcyjnych, a może lepiej przekształcę to zdanie na $W$ czasie lekcji dodawania liczb 1-100,", „Profesor der Astronomie an der Universität in Göttingen - profesor na uniwersytecie w Getyndze czy w uniwersytecie w Getyndze?”, "mit 20 Jahren - w wieku 20 lat czy w wieku lat 20, czy mając 20 lat - no nie wiem, wszystko brzmi dobrze”, „Czy napisać w wieku 15 lat, mając 15 lat, czy jako piętnastolatek?”, „Fundamentalsatz der Algebra przetłumaczyć jako zasadnicze twierdzenie algebry, fundamentalne prawo algebry, zasadnicze prawo algebry czy fundamentalne twierdzenie algebry?”, „mit Hilfe des Zirkels und des Lineals tłumaczyć przy pomocy cyrkla i linijki czy za pomoca cyrkla i linijki?”.

6. Analizowanie danych językowych w języku docelowym pod względem poprawnej pisowni, np. „W wieku piętnastu lat zapisać cyfrą czy słownie?”, „astronomii - jedno «i» czy dwa”, „chemii - pisownia polska? dwa «i»?", „... najważniejsze dzieła matematyczne, a może lepiej postawić kropkę i zacząć nowe zdanie?”, „als 9-jähriger - dziewięcioletni czy dziewięcio-letni?”, „An der Universität in Helmstedt, a może małą literą pisać na uniwersytecie?”, „dyrektor obserwatorium pisać małą czy wielką literą Dyrektor Obserwatorium?”, „Zahlen von 1-100 nie wiem, czy napisać z kreską czy od 1 do 100".

7. Stosowanie dodatkowych źródeł informacji, np. ,formułę rzędu arytmetycznego - sprawdzę to $\mathrm{w}$ słowniku $\mathrm{z}$ fachowym słownictwem, Paulina ma ten słownik”, „Standort może znaczy punkt, muszę potem sprawdzić, bo zabrali mi słownik”, „Princeps mathematicorum - tłumaczyć na polski, co to dokładnie oznacza, trzeba by zajrzeć do słownika łacińskiego".

\section{Strategie kompensacyjne}

- Opuszczanie informacji, np. „die Summenformel der arithmetischen Reihe - formuła rzędu arytmetycznego, nie wiem, a może opuszczę to słowo Summen, bo sumy formuły..., „Miterfindung - wspótwyna- 
lezienie napiszę wynalezienie, bo tamto brzmi dziwnie”, „Sternwarte napiszę krótko obserwatorium, bo wiadomo, jakie są obserwatoria", „der elektromagnetische Telegraph przetłumaczę na magnetyczny telegraf, przecież w tamtych czasach nie było prądu”.

\section{Strategie metakognitywne}

Poprawianie swojego tłumaczenia, np. ,fand er - znalazł, napiszę lepiej odkrył, bo jak to był naukowiec...”, „Als Sohn eines Saisonarbeiters - Dorastał jako syn pracownika sezonowego, lepiej wpisać Wychowywat się w rodzinie pracowników sezonowych", "frühzeitig - wcześnie, ale ładniej brzmi we wczesnym dziecinstwie”, „wuchs - wychowywat się? dorastał brzmi lepiej”.

\section{Strategie emocjonalne}

1. Pozytywna ocena swoich efektów, np. „Potencjał Gaußa odkrył ksiąze Brunszwigu już w jego wczesnym dzieciństwie - nie jest to tłumaczenie dosłowne, ale brzmi chyba dobrze?", „frühzeitig - wystarczajaco wcześnie, co ja piszę wcześnie fajnie mi wyszło".

2. Negatywna ocena swojej pracy, np. „seine Meisterschaft in der Mathematik - swój kunszt (talent, potencjat - ale to nie, bo znowu powtórzę to słowo) matematyka, swoja ogromna wiedzę w matematyce albo mistrzowskie zdolności matematyka - i tak brzmi głupio”, „Zrobił odkrycia matematyczne? - Nie! Dokonat waznych matematycznych odkryc", „Gauß był przede wszystkim jednym z największych matematyków swoich czasów (wszechczasów), który wpływał znacząco na wiele dziedzin nauki - nie podoba mi się to tłumaczenie. Może powinnam inaczej sformułować zdanie?”.

3. Wyrażanie swoich uczuć, np. „W wieku 15 lat, mając 15 lat, jako piętnastolatek - zastanowię się jeszcze, co zostawić”, „Princeps mathematicorum - nie wiem, jak to przetłumaczyć, matko co to jest?", "Großes erreichen sollte - nie wiem w jakim znaczeniu jest sollte", "Direktor der Sternwarte - dyrektor ale czego, nie znalazłam w moim słowniku tego słowa”, „[...] hatte er die wichtigsten mathematischen Weke durchgearbeitet - przerobił, nie pasuje mi w kontekście, ale jak inaczej?”, „berechnen - nie pasuje mi to słówko, co można obliczyć $\mathrm{w}$ planecie i ta planeta została dokładnie znaleziona na obliczonym miejscu? czy chodzi o obliczenie odległości do tej planety?”, „Znane 
sa jego pomiary Ziemi - czy na pewno o to chodzi?”, „Nie wiem, jak przetłumaczyć Meisterschaft w tym kontekście”, „W owym momencie nie mógł nikt przewidzieć - Muszę zmienić kolejność wyrazów w zdaniu”, „Augenblick - chwila mi nie bardzo pasuje”.

\section{Strategie społeczne}

Zadawanie pytań (współpraca z innym uczącym się), np. „Standort co to jest, spytam się Agaty”, „Weltruhm - nie znam tego słowa, zapytam Dominiki, ona ma słownik".

Ogółem wystąpiło 139 strategii. Najczęściej studenci stosowali strategie kognitywne (63 razy) a wśród nich dosłowne tłumaczenie na język ojczysty, analizowanie danych językowych pod względem stylistycznym i poprawnej pisowni w języku ojczystym. W dalszej kolejności są to strategie emocjonalne (43 użycia). Przeważają wśród nich strategie, przez które badani wyrażali swoje emocje, np. negatywnie oceniali własną pracę, co świadczy o tym, że są obiektywni i krytyczni wobec swoich dokonań. 24 razy zastosowano strategie pamięciowe, wykorzystując $\mathrm{w}$ procesie tłumaczenia przede wszystkim skojarzenia i kontekst. Rzadziej badani stosowali strategie kompensacyjne ( 9 użyć), tu opuszczanie informacji i metakognitywne, tj. poprawianie własnego tłumaczenia (8 razy). Tylko 6 osób wykorzystało strategie społeczne w swoich protokołach głośnego myślenia.

\section{Wybrane trudności w procesie ttumaczenia na język ojczysty}

W trakcie przekładu tekstów języka pisanego każdy tłumacz może natrafić na różne problemy. Aby sobie z nimi poradzić, musi on dysponować określonymi umiejętnościami (Dzierżanowska 1988: 13, 15; Snell-Hornby 1994: 10; Tomaszkiewicz 1996: 68; Lipiński 2000: 169-170; Płusa 2007: 23, 28), np.

- kompetencją językową zarówno w zakresie języka, w którym tekst został napisany (język oryginału), jak i języka, na który się tłumaczy (język przekładu, język docelowy), na poziomie leksykalno-semantycznym oraz morfologiczno-syntaktycznym;

- kompetencją kulturową obejmującą wiedzę na temat obu wspólnot komunikacyjnych, tj. znać realia kultury języka wyjściowego i docelowego;

- wiedzą encyklopedyczną, czyli wiedzą ogólną i specjalistyczną, obejmującą m.in. terminologię z zakresu wybranych języków fachowych;

- kreatywnością językową; 
- umiejętnością jasnego i ścisłego formułowania myśli oraz logicznego rozumowania.

$\mathrm{Z}$ uwagi na ograniczone ramy niniejszego artykułu, mogę jedynie zasygnalizować przykłady trudności, jakie mieli studenci podczas tłumaczenia. Trudności te podzieliłam na trzy grupy (za: Karczewska 2002: 129):

\section{Trudności wynikające z niedostatecznej znajomości języka oryginału:}

1. Trudności wywołane niezgodnością leksykalną, w przypadku gdy wyraz niemiecki ma dwa lub więcej znaczenia w języku polskim, np. badani mieli wątpliwości czy die wichtigsten mathematischen Werke tłumaczyć jako najważniejsze matematyczne mechanizmy czy najważniejsze dzieła matematyczne (Werk - 'dzieło, mechanizm'); czy $[\ldots]$ hatte er die [...] Werke durchgearbeitet tłumaczyć jako przerobit czy przestudiował dzieła (durcharbeiten - 'przerabiać, przestudiować), a może przeczytał. Świadczy to o tym, że niektórzy studenci nie zrozumieli, o czym jest tłumaczony przez nich tekst. A może lekceważąco podeszli do zadanej pracy domowej i nie zapoznali się $\mathrm{z}$ tekstem oryginału?

2. Trudności ze znajomością odpowiedniego ekwiwalentu w języku polskim, np. [...] bildete ihn aus tłumaczono jako kształcił go, dawał mu lekcje zamiast wykształcił go; in jenem Augenblick tłumaczono $w$ mgnieniu oka lub $w$ tym spojrzeniu zamiast $w$ tamtej chwili, $w$ tamtym momencie; [...] er [...] Großes erreichen sollte - tłumaczono będzie wielką osobistością, będzie wielkim mistrzem zamiast osiągnie wielkie rezultaty.

Z przytoczonych przykładów wynika, że badani nie postrzegają tłumaczonego tekstu jako całości, co powoduje, że mają trudności ze znalezieniem właściwych ekwiwalentów w języku, na który tłumaczą, stosownie do kontekstu, do którego odnosi się cały tekst.

\section{Trudności wywołane nieumiejętnym czytaniem tekstu wyjściowego i/lub niedostateczną znajomością języka przekładu}

1. Przenoszenie szyku wyrazów z języka tekstu tłumaczonego do tekstu tłumaczenia:

a) kopiowanie szyku zdania charakterystycznego dla języka oryginału w języku docelowym, np. Der Standort des Planeten Ceres, 
der nur einmal gesehen worden war, wurde von Gauß berechnet, und der Planet wurde genau an der berechneten Stelle gefunden. - Położenie planety Ceres, która tylko raz widziano, zostało przez Gaußa obliczone i planeta została dokładnie w tym położeniu znaleziona.

b) umieszczanie w języku polskim przydawki klasyfikującej przed rzeczownikiem, np. sezonowy robotnik zamiast robotnik sezonowy (Nowy słownik poprawnej polszczyzny 2002: 885) czy algebraiczne równanie zamiast równanie algebraiczne (Nowy słownik poprawnej polszczyzny 2002: 851).

W języku polskim ta sama część zdania, np. podmiot lub orzeczenie, może zajmować różne pozycje. Jednak całkowita dowolność szyku wyrazów w zdaniu sprawiłaby, że w niektórych wypadkach straciłoby ono sens. Dlatego też istnieją pewne granice swobody szyku wyrazów w języku polskim i grupę podmiotu umieszczamy przed grupą orzeczenia, a przydawki klasyfikujące, wskazujące najistotniejszą cechę przedmiotu, jego miejsce w zbiorze czy systemie stawiamy po rzeczowniku (Jaworski 1980: 171-173; Nowy słownik poprawnej polszczyzny 2002: 1729).

Studenci wykazują brak czujności, tłumaczą dosłownie z języka niemieckiego i przenoszą szyk niemiecki do języka polskiego, naruszając normy składniowe języka ojczystego.

2. Błędy w zakresie składni, tu stosowanie strony biernej w tłumaczeniu na język polski: C.Fr. Gauß wurde am 30.4. im Jahre 1777 in Braunschweig geboren. - C.Fr. Gauß zostat urodzony w dniu 30.4. w roku 1777 w Brunszwiku, zamiast C.Fr. Gauß urodził się... Warto w tym kontekście dodać, że formy strony biernej rzadziej są używane w tekstach polskich; uchodzą za znamię stylu oficjalnego, urzędowego. Tam, gdzie jest to możliwe, zaleca się stosowanie strony czynnej lub konstrukcji nieosobowych (Der kleine Duden 1997: 117; Nowy słownik poprawnej polszczyzny 2002: 1627).

3. Trudności na poziomie leksykalnym w zakresie semantycznej ekwiwalencji środków leksykalnych, tu z doborem właściwego ekwiwalentu, np. seine Meisterschaft in der Mathematik tłumaczono jako jego perfekcję $w$ matematyce zamiast jego mistrzostwo w matematyce; In ärmlichen Verhältnissen tłumaczono jako $w$ ubogich warunkach, w biednych warunkach, lepiej brzmi $w$ trudnych warunkach materialnych.

4. Trudności wywołane niewystarczającą znajomością zasad polskiej pisowni, np. student zastanawia się, czy piszemy chemii czy ${ }^{\star}$ chemi, * pomiary Ziemii czy pomiary Ziemi. 


\section{Trudności spowodowane niewystarczającą wiedzą ogólną oraz fachową}

1. Trudności wynikające z nieznajomości terminologii z określonej dziedziny, tu języka matematyki i fizyki, np. Standort des Planeten Ceres tłumaczono jako miejsce na planecie Ceres, miejsce planety Ceres zamiast położenie planety Ceres na sklepieniu niebieskim; die Summenformel der arithmetischen Reihe tłumaczono jako formułe sumująca arytmetycznego rzędu, formułe sumy $w$ arytmetyce, wzór dodawania szeregu arytmetycznego, wzór sumy ciagu arytmetycznego, wzór ciagu arytmetycznego, formułe dodawania szeregu arytmetycznego zamiast wzór sumy postępu arytmetycznego (ciagu arytmetycznego); komplexe Zahlen tłumaczono jako liczby złożone, liczby kompleksowe zamiast liczby zespolone, Lehrsatz tłumaczono jako założenie, aksjomat zamiast twierdzenie; ein regulärer Siebzehneck tłumaczono jako siedemnastokąt prosty zamiast siedemnastokąt foremny; Seiten eines regulären Siebzehnecks przekładano jako ściany zamiast boki siedemnastokata foremnego.

2. Trudności wynikające $\mathrm{z}$ braku odpowiedniej wiedzy, tj. znajomości realiów odnoszących się zarówno do języka oryginału, jak i języka przekładu, tu trudności z przekładem nazwy własnej (nazwy geograficznej); badani zastanawiali się, czy tłumaczymy nazwę na język polski, czy zostawiamy w wersji oryginalnej, np. Braunschweig czy Brunszwik lub ${ }^{\star B}$ Brunszwig. Problemem dla niektórych osób była także nieznajomość polskiego odpowiednika.

3. Trudności z łaciną, Princeps mathematicorum tłumaczono jako książe matematyki, książę nauk matematycznych, a nie jako książe matematyków. (Studenci mieli język łaciński na pierwszym roku studiów. Można przypuszczać, że w niewystarczającym zakresie).

$Z$ analizy przekładów wynika, że studenci wykazują tendencję do tłumaczenia dosłownego na język polski. Dlatego u wielu osób tłumaczony tekst jest kalką struktur tekstu w języku niemieckim. Podstawową zasadę tłumaczenia sformułował w IV wieku św. Hieronim w jednym ze swoich listów (Epistula LVII ad Pammachium, die optimo geriere interpretand), w którym pisał, aby nie tłumaczyć verbum e verbo, sed sensum exprimere de sensu (przytaczam za: Dzierżanowska 1988: 16; Pieńkos 1993: 47), czyli słowo w słowo, a uchwycić sens tekstu, by skutecznie przekazać jego treść. Należy bowiem pamiętać, że tłumaczenie słowo po słowie może pociągnąć za sobą naruszenie norm języka docelowego, czego dowodem są trudności, jakie mieli studenci i popełnione przez nich błędy translatorskie. W przedmiotowym tekście występują np. 
terminy funkcjonujące $\mathrm{w}$ języku niemieckim $\mathrm{w}$ określonej formie przyjętej przez świat nauki, a zastosowanie zasady dosłowności w przekładzie tekstu zakłóca ich prawidłowe zrozumienie (Pieńkos 1993: 127). Adekwatność tłumaczenia nie polega na dosłownym przełożeniu słów, wyrażeń i zwrotów, lecz na przekazie pełnej i jednoznacznej treści (Płusa 2007: 23).

Aby dobrze tłumaczyć, trzeba znać temat, który stanowi przedmiot tłumaczenia, mieć szeroką wiedzę ogólną i specjalistyczną oraz doskonale znać zarówno język ojczysty, jak i obcy. Studenci muszą mieć ponadto określony zasób wiadomości z zakresu gramatyki i leksyki nie tylko języka, z którego tłumaczą, ale i tego, na który tłumaczą.

Błędy w trakcie tłumaczenia wynikają z braku odpowiedniej wiedzy na temat zasad przekładu, z niewiedzy na poziomie językowym, z nieznajomości dziedziny, do której należy tekst źródłowy, a także z nieumiejętnego czytania tekstu oryginału.

\section{Uwagi końcowe}

Tłumaczenie w procesie nauki języka obcego ma funkcję kształcącą, ponieważ uczący się poznaje właściwości obcego i własnego systemu językowego, uczy się nie tylko zrozumienia i opanowania obcojęzycznej leksyki i gramatyki, lecz także usprawnia władanie językiem ojczystym i kształci umiejętność precyzyjnego wyrażania myśli. Stosowanie ćwiczeń tłumaczeniowych w procesie glottodydaktycznym wzbogaca również techniki nauczania i uczenia się języka obcego i ojczystego (Płusa 2007: 11, 16).

$\mathrm{Z}$ analizy tłumaczeń wykonanych techniką głośnego myślenia wynika, że wśród stosowanych przez studentów strategii uczenia się przewagę mają strategie kognitywne, świadczące o kreatywności badanych, która przejawia się np. w użyciu myślenia dedukcyjnego, kombinowaniu struktur czy opisywaniu różnych technik ułatwiających zrozumienie tekstu. Autorzy cytowanych przeze mnie przykładów nie są zawodowymi tłumaczami. Ponieważ nie mają jeszcze zajęć $\mathrm{z}$ translatoryki, w swoich próbach tłumaczenia natrafili na wiele trudności wynikających z nieznajomości technik przekładu oraz spowodowanych niewiedzą na poziomie językowym i brakiem wystarczającej wiedzy ogólnej i kulturowej. Dlatego tłumaczenie powinno być jedną z metod stosowanych w procesie nauczania każdego języka. Dzięki temu uczący się stają się wrażliwi na umiejętność poprawnego wypowiadania się w mowie i w piśmie nie tylko w języku obcym, lecz także w języku ojczystym zarówno w zakresie języka ogólnego, jak i specjalistycznego. 


\section{Literatura}

Der kleine Duden. Mała gramatyka języka niemieckiego, 1997, Warszawa.

Dzierżanowska, H., 1988, Przekład tekstów nieliterackich. Na przykładzie języka angielskiego, Warszawa.

Encyklopedia szkolna. Matematyka, 1990, Warszawa.

Grucza, F., 1981, „Fremdsprachenunterricht und Übersetzung”, [w:] Übersetzen und Fremdsprachenunterricht, K.R. Bausch, F.R. Weller (red.), Frankfurt/M, s. 32-45.

Jaworski, M., 1980, Podręczna gramatyka języka polskiego, Warszawa.

Jäger, G., 1981, „Übersetzen und Übersetzung” [w:] Übersetzen und Fremdsprachenunterricht, K.R. Bausch, F.R. Weller (red.), Frankfurt/M, s. 61-72 .

Karczewska, D., 2002, „O błędach w tłumaczeniu”, [w:] Język rodzimy a język obcy. Komunikacja - przekład - dydaktyka, A. Kopczyński, U. Zaliwska-Okrutna (red.), Warszawa, s. 129-135.

Königs, F.G., 2000, „Übersetzen im Deutschunterricht? Ja, aber anders”, [w:] Fremdsprache Deutsch. Übersetzen im Deutschunterricht, Heft 23, s. 6-13.

Lelewicz, M., Linkiewicz, H., 1967, Deutsch. Podręcznik języka niemieckiego dla lektoratów Studiów Nauczycielskich, Warszawa.

Lipiński, K., 2000, Vademecum tłumacza, Kraków.

Michońska-Stadnik, A., 1996, Strategie uczenia się i autonomia ucznia w warunkach szkolnych, Wrocław.

Nowy słownik poprawnej polszczyzny, 2002, A. Markowski (red.), Warszawa.

Pieńkos, J., 1993, Przekład i tłumacz we współczesnym świecie. Aspekty lingwistyczne i pozalingwistyczne, Warszawa.

Płusa, P., 2007, Rozwijanie kompetencji przekładu i kształcenie tłumaczy, Katowice.

Snell-Hornby, M., 1994, „Einleitung. Übersetzen, Sprache, Kultur”, [w:] M. Snell-Hornby, Übersetzungswissenschaft, Tübingen, s. 9-29.

Strasser, M., 2008, Verständigungsstrategien bei sehr geringen Sprachkenntnissen. Eine explorative Studie zur Kommunikation unter Bedingungen der Interkomprehension, Wien.

Szarska-Wieruszewska, J., 2004, Lernstrategien als Grundlage der lerntypischen Fehlerbehandlungen. Forschungsstudien am Beispiel der Deutsch lernenden, polnischen Studenten, Hamburg.

Tomaszkiewicz, T., 1996, „Operacje procesu przekładu”, [w:] Współczesne tendencje przekładoznawcze. Podręcznik dla studentów neofilologii, A. Pisarska, T. Tomaszkiewicz (red.), Poznań, s. 63-214. 
Witkowska, M., 2010, „Zastosowanie protokołu głośnego myślenia i retrospekcji w badaniach autorefleksji przyszłych nauczycieli języka angielskiego", [w:] Neofilolog, nr 34, s. 147-157.

\section{Think-aloud protocols in translation into the mother tongue at the advanced level Summary}

The purpose of this paper is to analyse think-aloud protocols in translations from a foreign language into the mother tongue and to present the function of translation in the language teaching process. Research on the translation process with the application of think-aloud protocols gives a running commentary on mental activities during the process of translation. The author investigates language learning strategies in translations from German into Polish written by students of Applied Linguistics. The most frequent strategies used by the respondents in the study were cognitive strategies, word-for-word translation and data analysis. The aim of the present study was also to reveal and to describe problems that occur during the translation process on examples taken from students' works. Students' verbalisations provide us with the opportunity of acquiring a better understanding of difficulties they encounter with the foreign language, the mother tongue or the language for special purposes as well as difficulties in reading texts in the source language.

Keywords: think-aloud protocols, foreign language teaching and learning processes, learning strategies, mother tongue

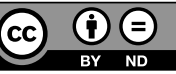

